\title{
PENERAPAN MOTION FLAT DESIGN PADA OBJECT VIDEO PROMOSI CASE STUDI STMIK DHARMA WACANA
}

\author{
${ }^{1}$ Arbiyansyah Gusti Pratama, ${ }^{2}$ Ridwan Yusuf, ${ }^{3}$ Budi Sutomo \\ ${ }^{1}$ Program Studi Teknik Informatika, STMIK Dharma Wacana Metro \\ 2,3 Dosen Tetap Teknik Informatika, STMIK Dharma Wacana Metro \\ Jalan Kenangan No.3 Mulyojati Kota Metro \\ Email : arbiyansyah10@gmail.com
}

\begin{abstract}
ABSTRAK
STMIK Dharma Wacana Metro merupakan Perguruan Tinggi Swasta dibawah naungan Yayasan Dharma Wacana yang mempunyai beberapa media promosi diantaranya dengan memakai sistem door to door, media cetak, website dan video sebagai media promosi. media cetak menggunakan banner dan brosur, website digunakan dalam kegiatan promosi untuk memberikan informasi dan untuk video memakai video profile. Dalam sebuah promosi Agar produk atau jasa dapat diketahui pelanggan dengan sangat cepat, perlu adanya suatu cara yang unik. Dengan memanfaatkan teknologi pada saat ini. Teknologi pada media promosi saat ini sangat banyak sekali salah satunya adalah dengan cara memanfaatkan teknologi Video motion graphic flat design. Motion graphic adalah media yeng menggunakan rekaman video animasi yang menciptakan unsur gerak dan dikombinasikan dengan audio. Sedangkan Flat design adalah sebuah desain dengan gaya minimalis yang berfokus pada ilustrasi dua dimensi dan warna yang cerah.
\end{abstract}

Kata kunci: Video, Teknik Motion Graphic Flat Design

\section{PENDAHULUAN}

Perguruan Tinggi Dharma Wacana Metro Merupakan Perguruan Tinggi dibawah naungan Yayasan Pendidikan yang beralamat di Jl. Kenangan No.03 Mulyojati Metro Barat, Kota Metro, Lampung 34111. Kegiatan promosi yang sudah dilakukan kampus STMIK Dharma yaitu dengan menggunakan sistem door to door, media cetak ataupun dengan video sebagai media promosi. Untuk media cetaknya kampus STMIK Dharma menggunakan banner dan brosur. Sedangkan untuk video promosi yang dipakai adalah video profile. Disamping itu STMIK Dharma Wacana mempunyai website sendiri, website tersebut dapat pula sebagai sarana dalam menyampaikan sebuah informasi dalam bentuk promosi.

Promosi merupakan salah satu variabel di dalam marketing mix yang sangat penting dilaksanakan oleh perusahaan dalam pemasaran produk atau jasanya (Fetrizen, Nazaruddin Aziz, 2019). Tidak dapat dipungkiri banyaknya media promosi pada saat ini dimanfaatkan bagi para penjual jasa atau produk untuk menjual jasa atau produknya dengan sangat cepat. Peran marketing dalam hal promosi ini sangatlah penting, karena promosi dapat dilakukan melalui dua jalur yakni Above The Line (ATL) dan Below The Line (BTL). Media lini atas (Above the line media) sebuah kegiatan promosi yang menggunakan media massal seperti media tentang pengiklanan menggunakan media cetak, elektronik dan media luar ruang. Media lini bawah (Below the line media) yang berisi Direct Mail, pameran, Point of Sale, Display, Kalender, agenda, gantungan kunci, atau tanda mata.

Agar produk atau jasa dapat diketahui pelanggan dengan sangat cepat, perlu adanya suatu cara yang unik. Dengan memanfaatkan teknologi pada saat ini. Teknologi pada media promosi saat ini sangat banyak sekali salah satunya adalah dengan cara memanfaatkan teknologi Video motion graphic flat design. Motion graphic adalah media yeng menggunakan rekaman video animasi yang menciptakan unsur gerak dan dikombinasikan dengan audio. Flat Design adalah sebuah desain dengan gaya minimalis yang berfokus pada ilustrasi dua dimensi dan warna yang cerah.

\section{METODE PENELITIAN}

- Metode Development Life Cycle

Dalam hal ini penulis memakai metode MDLC (Multimedia Development Life Cycle) yang terbagi dalam 6 tahapan, Akan tetapi dalam penyelesaiannya hanya sampai ditahapan testing. 


\section{Konsep}

Tahap ini merupakan tahap awal merumuskan dasar dasar konsep, dan di tahap ini adalah tahap dimana tujuan proyek serta pengguna hasil akhir proyek ditentukan

\section{Desain}

Di dalam tahap desain dilakukan perincian terhadap langkah langkah yang akan dilakukan, bagaimana cara melaksanakan dan bahan yang dibutuhkan selama pelaksanaan proyek.

\section{Pengumpulan Materi}

Tahap ini merupakan proses untuk pengumpulan segala sesuatu yang dibutuhkan dalam pembuatan video promosi. Antara lain pengumpulan audio, video dan gambar - gambar yang akan di masukan di dalam penyajian video promosi.

\section{Pembuatan}

Tahap pembuatan adalah tahap dimana semua objek atau bahan multimedia dibuat. Pembuatan video promosi berdasarkan pada consept dan design.

\section{Testing}

Pada tahap ini adalah tahap uji coba dari proyek yang sudah di buat. Uji coba dari proyek ini dilakukan dengan cara menjalankan video di berbagai media player

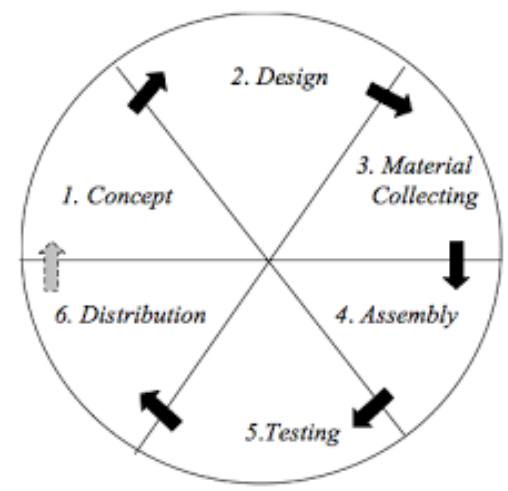

Gambar 1. Tahapan MDLC

\section{HASIL DAN PEMBAHASAN}

\section{Konsep}

Ide cerita dari kampus STMIK Dharma Wacana Metro adalah mempromosikan kampus dalam bentuk video promosi menggunakan teknik motion graphic flat design. Teknik yang dipakai menekankan pada warna-warna yang cerah. Dalam perancangan video promosi dibuat dalam 9 tahapan adegan atau scene dengan waktu 2 menit 50 detik.

\section{Desain}

Pada tahap ini pembuatannya menggunakan stroryboard. Storyboard ini harus sesuai dengan ide cerita yang telah dibuat agar tercipta kesesuaian antara keduanya. Hal ini sangat diperlukan karena storyboard akan digunakan sebagai bahan acuan untuk proses produksi.
Tabel 1. Tabel Storyboard

\begin{tabular}{|c|c|c|c|}
\hline No & Visual & Scenario & Waktu \\
\hline 1. & & $\begin{array}{c}\text { Opening berupa } \\
\text { logo STMIK } \\
\text { Dharma } \\
\text { Wacana Metro }\end{array}$ & $\begin{array}{c}00: 00 \\
- \\
00: 03\end{array}$ \\
\hline 2. & & $\begin{array}{c}\text { Menampilkan } \\
\text { karakter pria } \\
\text { yang } \\
\text { bermonolog }\end{array}$ & $\begin{array}{c}00: 03 \\
- \\
00: 38\end{array}$ \\
\hline 3. & & $\begin{array}{c}\text { Menceritakan } \\
\text { tentang STMIK } \\
\text { Dharma } \\
\text { Wacana Metro }\end{array}$ & $\begin{array}{c}00: 38 \\
- \\
01: 02\end{array}$ \\
\hline 4. & & $\begin{array}{c}\text { Menampilkan } \\
\text { program studi } \\
\text { yang ada di } \\
\text { STMIK } \\
\text { Dharma } \\
\text { Wacana Metro }\end{array}$ & $\begin{array}{c}01: 02 \\
- \\
01: 14\end{array}$ \\
\hline 5. & & $\begin{array}{c}\text { Menampilkan } \\
\text { organisasi } \\
\text { kemahasiswaan }\end{array}$ & $\begin{array}{c}01: 14 \\
- \\
01: 28\end{array}$ \\
\hline 6. & & $\begin{array}{c}\text { Menampilkan } \\
\text { icon icon } \\
\text { fasilitas }\end{array}$ & $\begin{array}{c}01: 28 \\
- \\
01: 35\end{array}$ \\
\hline 7. & & $\begin{array}{c}\text { Menampilkan } \\
\text { prospek kerja } \\
\text { ketika sudah } \\
\text { lulus }\end{array}$ & $\begin{array}{c}01: 35 \\
- \\
01: 42\end{array}$ \\
\hline 8. & & $\begin{array}{l}\text { Menampilkan } \\
\text { tata cara } \\
\text { pendaftaran } \\
\text { online }\end{array}$ & $\begin{array}{c}01: 42 \\
- \\
02: 37\end{array}$ \\
\hline 9. & $Q$ & $\begin{array}{c}\text { Menampilkan } \\
\text { dari karakter } \\
\text { laki-laki } \\
\text { berambut } \\
\text { pendek turun } \\
\text { dari sebuah } \\
\text { roket }\end{array}$ & $\begin{array}{c}02: 37 \\
- \\
02: 50\end{array}$ \\
\hline
\end{tabular}

\section{Pengumpulan Materi}

Tahapan ini adalah pengumpulan materi yang dibutuhkan untuk pembuatan video. Materi 
tersebut didapatkan dari kampus STMIK Dharma Wacana Metro dan internet berupa file file multimedia. File multimedia yang dikumpulkan dari internet yaitu karakter animasi siswa yang baru lulus SMA sederajat, icon icon organisasi kemahasiswaan, fasilitas, audio sound effect dan audio backsound. Untuk file multimedia yang didapatkan dari kampus yaitu logo kampus, gedung kampus, logo BEM, logo HIMA dan audio berisikan rekaman dengan format $\mathrm{m} 4 \mathrm{a}$ file. Audio tersebut nantinya dimasukan didalam video sesuai dengan scene- scene yang sudah di desain.

\section{Pembuatan}

Pada tahapan pembuatan video ini memakai durasi 2 menit 50 detik dengan resolusi frame $1280 \times 720$ pixels dan format H.264 (MP4). Untuk audionya meggunakan format $A A C$. Software yang digunakan yaitu software adobe premiere dan beberapa software pendukung seperti adobe after effect dan adobe illustrator yang masing masing mempunyai tugas tersendiri.

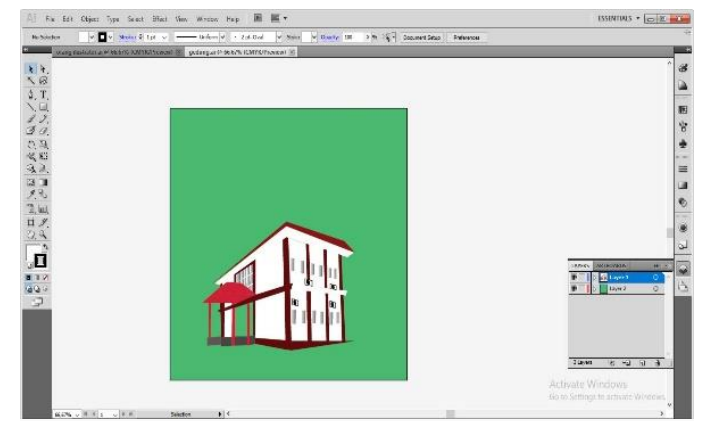

Gambar 2. Desain gedung menggunakan adobe illustrator

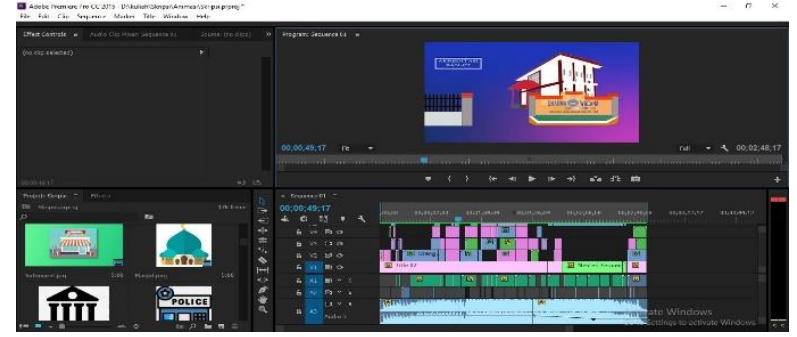

Gambar 3. Aplikasi adobe premiere pro untuk membuat motion graphic

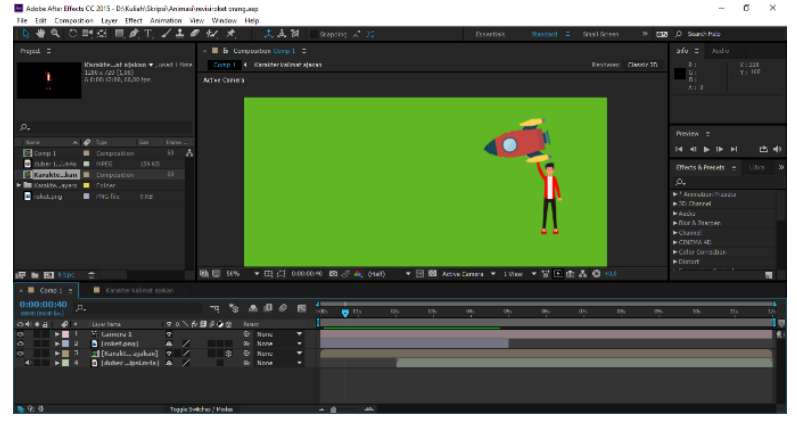

Gambar 4. Pembuatan animasi menggunakan adobe after effect

\section{Testing}

Tahap terakhir dari proses ini adalah testing atau juga disebut uji coba,pada uji coba video promosi ini dilakukan dengan menggunakan media pemutar video

Tabel 2. Tabel Pengujian

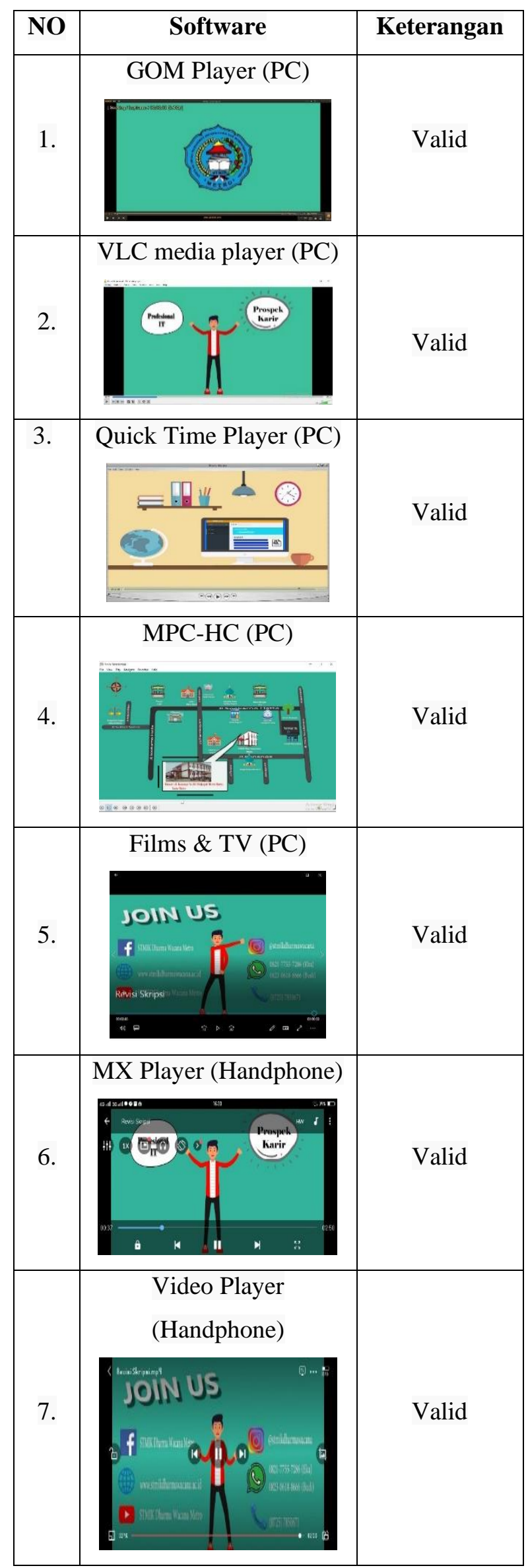




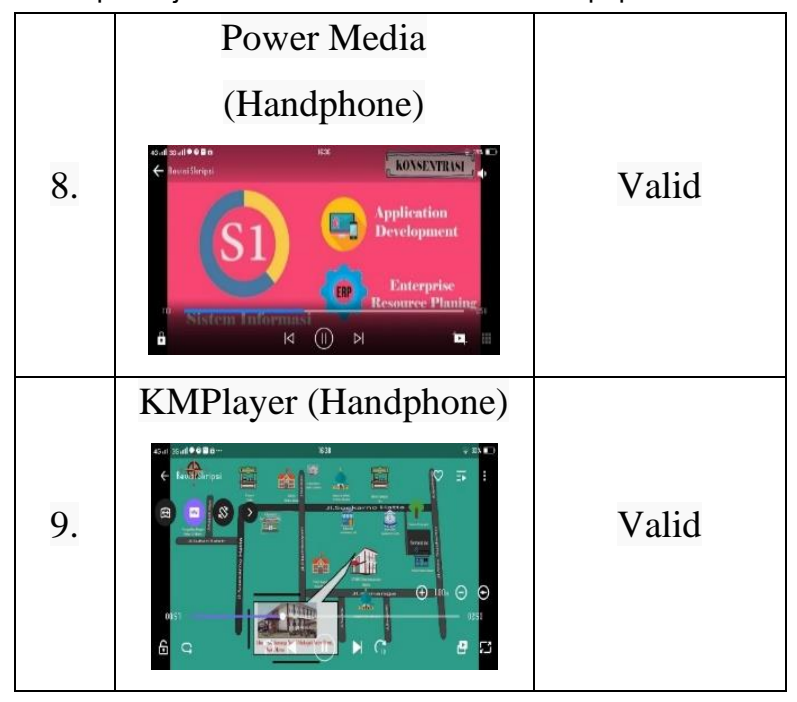

\section{KESIMPULAN DAN DARAN}

\section{A. Kesimpulan}

1. Dengan menggunakan teknik motion graphic flat design dalam sebuah video promosi ini, dapat digambarkan pada karakter dan ikonikonnya didesain secara minimalis dan tidak memfokuskan detail gerakkan yang diciptakan objek seperti gerak mulut, gerak kepala, gerak tangan, dan kerap kali menciptakan suatu gerakan objek secara menyeluruh kearah yang sama.

2. Ikon yang terdapat didalamnya mudah dipahami serta tipografi yang dipakai didesain untuk kemudahan penonton dan warna yang simple namun menarik merupakan kelebihan dari teknik motion graphic flat design.

\section{B. Saran}

1. Media promosi dengan teknik Motion Graphic ini dapat berkembang lagi dengan menggunakan objek 3D atau menggabungkan objek nyata dengan objek 2D/3D, sehingga media promosi ini akan terus berkembang.

2. Dalam mendesain objek vector dan proses editing video, pemilihan warna harus diperhatikan antara objek satu dengan yang lainnya, karena warna memiliki pengaruh terhadap ketertarikan penonton. Pelajari lebih banyak mengenai teknik - teknik dalam pembuatan motion graphic karena motion graphic ini selalu mengikuti perkembangan zaman dari segi desain maupun estetika konten yang ditampilkan.

\section{DAFTAR PUSTAKA}

1. STMIK Dharma Wacana. (2017)."Buku Panduan Penulisan Skripsi STMIK Dharma Wacana Revisi III: 03 Juni 2017.

2. Fadhly Abdillah, Damar Adhiguna, Agus Sevtiana. (2017).'Perancangan Video Profile
Sebagai Media Promosi STMIK CIC Dengan Tehnik Motion Graphic Menggunakan Perangkat Lunak Komputer Graphic". Vol. 7, No.1 Mei 2017.

3. Erlangga Rachmansyah, Umi Khabibah. (2019).'Pembuatan Video Iklan Menggunakan Adobe Premiere Pro CC Sebagai Media Promosi Untuk Meningkatkan Penjualan Pada Amstirdam Coffe And Roastery Malang". Vol.5, No.1, Juni 2019

4. Muhamad Rendi Nurmansyah, Ike Atikah Ratnamulyani, Ali Alamsyah Kusumadinata. (2019).'Hubungan Motion Graphic Sebagai Konten Promosi Sekolah di Media Sosial". Vol. 1 No. 2 Juli 2019

5. Henri Septanto, Harya Bima Dirgantara. (2020)."Perancangan Media Pembelajaran Pengenalan Hewan Berbasis Animasi Multimedia Untuk Anak-anak TK". Vol 15 No 1, Januari 2020

6. Penda Sudarto Hasugian. (2018).."Perancangan Website Sebagai Media Promosi dan Informasi". Volume 3 No 1 Maret 2018

7. Syifa Fauzia, Fenty Eka Muzayyana Agustin, Undang Syaripudin, Yuditha Ichsani. (2016)."Perancangan Prototype Tampilan Antar Muka Pengguna Aplikasi Web Kamardagang.com Dengan Teknik Flat Design Pada PT. Selaras Utama Internasional". Vol 9 No. 2, Oktober 2016.

8. Indah Liani, Ari Saputro (2019),"Rancangan Desain Website Responsif Sebagai Sarana Informasi Pada SMK Pustek Serpong". Vol. 2 No. 5, September 2019.

9. Ria Diajeng Anita, Fitri Marisa. (2017)."Rancangan Video Media Promosi Berbasis Motion Graphic 2D Untuk Meningkatkan Jumlah Mahasiswa Universitas Widyagama Malang". Vol. 1, No. 2, Januari 2017

10.Luther, Arc C. (1994). Authoring Interactive Multimedia. AP Professional. Boston 